\title{
Qual o lugar da Educação de Jovens e Adultos nos museus brasileiros?
}

\author{
What is the place of the Youngs and Adults Education in Brazilian museums?
}

\author{
Magaly Cabral*
}

Palavras chave:

Educação de Jovens e

Adultos (EJA)

Museu

Cidadania

Keywords:

Youngs and

Adults'Education

Museum

Citizenship
Resumo: O presente texto apresenta três projetos desenvolvidos com os alunos do Programa de Educação de Jovens e Adultos (PEJA) do município do Rio de Janeiro no Museu da República, unidade museológica do Instituto Brasileiro de Museus (IBRAM)/Ministério do Turismo. Um dos projetos foi agraciado com o V Prêmio Ibermuseus de Educação 2014, em primeiro lugar, na Categoria I, e com o prêmio Best Practice, concedido pelo Comitê Internacional de Educação e Ação Cultural (CECA) do Conselho Internacional de Museus (ICOM). A partir desses projetos e, principalmente, desses prêmios, o Museu conseguiu a abertura de suas portas uma vez por mês, à noite, para receber os alunos da Educação de Jovens e Adultos (EJA) com mais frequência, fazendo com que a EJA começasse a encontrar seu lugar num museu brasileiro e seus estudantes começassem a praticar a Cidadania.

Abstract: This text presents three projects which were developed with the students of the Youngs and Adults Education Program of the city of Rio de Janeiro, in the Museum of Republic, a museological unity of the Brazilian Institut of Museums/Ministry of Tourism. One of the projects received the V Ibermuseums Award of Education 2014, first place, Category I, as well as the Best Practice Award offered by the Committee for Education and Cultural Action (CECA) of the International Council of Museums (ICOM). Thanks to these projects, and specially to the awards, the Museum of Republic got to open its doors once a month, in the night, to receive the students of Youngs and Adults Education more frequently, making possible that this kind of Education meets its place in a Brazilian museum and that its students began to practice their Citizenship.

Recebido em 12 de julho de 2021. Aprovado em 07 de outubro de 2021.

\footnotetext{
* Professora, Pedagoga, Museóloga, Mestre em Educação. Membro do Comitê para Educação e Ação Cultural (CECA) do Conselho Internacional de Museus (ICOM). Participante do Grupo de Pesquisa Educação Museal (GEPEM) do Museu Histórico Nacional; ex-Coordenadora Regional do CECA/ICOM para América Latina e Caribe (julho/1995 a julho/1998); ex-Coordenadora do CECA-Brasil/ICOM (fevereiro/2005 a agosto/2007; março a agosto 2001). E-mail: magalycabral@globo.com.
} 
Não é possivel respeito aos educandos, à sua dignidade, a seu ser formando-se, à sua identidade fazendo-se, se não se levam em consideração as condiçôes em que eles vêm existindo, se não se reconbece a importância dos "conbecimentos de experiência feitos" com que chegam à escola. $O$ respeito devido à dignidade do educando não me permite subestimar, pior ainda, zombar do saber que ele traz consigo para a escola. (Paulo Freire)

\section{Introdução}

Todo museu tem, entre suas ações, projetos de atendimento a escolares, seja em visitas mediadas seja em projetos específicos. Mas dificilmente encontramos museus que oferecem atendimento aos alunos da Educação de Jovens e Adultos. Daí a pergunta: qual o lugar da Educação de Jovens e Adultos nos museus brasileiros? Pode-se afirmar que não existe esse lugar. Isso porque, regra geral, os museus brasileiros não abrem à noite, que é o horário no qual se dá a Educação de Jovens e Adultos (EJA). Além de diversos fatores como, por exemplo, a segurança do Museu, é necessário um grande esforço e interesse da Equipe Educativa de um museu para que tal atendimento possa acontecer. Felizmente, a Equipe Educativa do Museu da República, unidade museológica do Instituto Brasileiro de Museus (IBRAM)/Ministério do Turismo, se propôs a desenvolver projetos com os alunos do Programa de Educação de Jovens e Adultos (PEJA) no município do Rio de Janeiro.

$\mathrm{O}$ presente texto apresenta três projetos desenvolvidos no citado museu, tendo um deles sido agraciado com o V Prêmio Ibermuseus de Educação 2014, em primeiro lugar, na Categoria I, e com o prêmio Best Practice, concedido pelo Comitê Internacional de Educação e Ação Cultural (CECA) do Conselho Internacional de Museus (ICOM). ${ }^{1}$ Esses projetos e, principalmente, esses prêmios auxiliaram na luta para que as autoridades mantenedoras do Museu da República concordassem com a ampliação do valor pago à empresa prestadora de serviços de segurança para a abertura do Museu uma vez por mês, à noite, e, assim, passasse a receber turmas do Programa de
Educação de Jovens e Adultos (PEJA) em visita ao museu.

\section{O primeiro projeto - Todos Juntos: pela autonomia e cidadania no espaço da República}

O Museu da República define-se como um espaço de cidadania e tem como missão preservar, investigar e comunicar os testemunhos vinculados à história da República Brasileira.

Ao definir-se como um espaço de cidadania, o Museu da República investe, por meio de projetos pedagógicos e açôes culturais, na democratização do acesso aos acervos que preserva, a começar pelo próprio palácio no qual está situado, seu jardim histórico e seu entorno, locais de diálogo permanente com as manifestaçôes culturais da cidade, do estado e do país.

No ano de 2008, a Constituição da República Federativa do Brasil completou 20 anos. Esta Carta Magna foi conclamada, por diversos políticos, intelectuais e artistas que participaram de sua elaboração, como a Constituição Cidadã. No final da década de 1980, o país vivia um momento de redemocratização. Com o fim da ditadura militar, a sociedade brasileira sentiu a necessidade de que amplas reformas constitucionais fossem feitas, o que poderia garantir os direitos fundamentais de cada brasileiro, como também estabelecer deveres e limites ao Estado, para que tal período ditatorial jamais se repetisse em nosso país.

Neste sentido, em 15 de novembro de 2008, o Museu da República, com o apoio da Fundação Ford, deu início ao projeto "Constituição de 1988: a voz e a letra do cidadão", que compreendia diversas ações, entre elas a inauguração da exposição de mesmo nome e o desenvolvimento do projeto educativo "Todos Juntos: pela autonomia e cidadania no espaço da República”, que tinha a exposição como fio condutor. $\mathrm{O}$ projeto foi desenvolvido no período de março a outubro de $2009^{2}$, com uma escola vizinha ao Museu, o Centro Integrado de Escola Pública (CIEP) Tancredo Neves. ${ }^{3}$

Segundo dados fornecidos pela direção do CIEP Tancredo Neves à Coordenação de Educação 
do Museu, em dezembro de 2008, a escola possuía 798 alunos, contemplando a Educação Infantil e o Ensino Fundamental. Deste universo, 356 alunos eram do Programa de Educação de Jovens e Adultos (PEJA), estudantes do período noturno, e estavam distribuídos em quatorze turmas do 2ㅇ ao 9o ano. Esse contingente correspondia a $44,6 \%$ do total de alunos do CIEP. Os outros 442 alunos eram do período diurno, distribuídos entre a educação infantil, com seis turmas, e a educação básica, do 1o ao 5 o ano, com doze turmas.

Em fevereiro de 2009, foram feitas entrevistas com os alunos do Programa de Educação de Jovens e Adultos (PEJA), alunos que, como já dito, estudam à noite. Constatou-se que $90 \%$ dos alunos não conheciam o Museu, embora estudando e morando vizinhos a ele. E nem mesmo frequentavam o jardim do Museu, aberto todos os dias da semana aos moradores do bairro. Os alunos do PEJA são alunos trabalhadores: empregadas domésticas, faxineiros, taxistas, porteiros, vendedores ambulantes, entre outras profissóes, cuja idade varia entre 15 e 70 anos de idade. São moradores do bairro e arredores onde se situa o Museu, a maioria em favelas do bairro. Assim, e graças ao apoio da Fundação Ford, foi possível abrir o Museu à noite, com segurança, para receber esses alunos. E fez-se questão de que entrassem pela porta principal do Museu.

Como resultado final de todas as ações, foi montada uma exposição sobre a memória do projeto, inaugurada em 15 de novembro de 2009, por ser uma data comemorativa aos 120 anos da proclamação da República e ao aniversário de 49 anos do Museu. A exposição ocupou o mesmo espaço onde estava a exposição "A Constituição de 1988: a voz e a letra do cidadão". A museografia ficou a cargo do setor de Museologia do Museu da República, seguindo as orientaçóes do roteiro elaborado pelos educadores do projeto e a Coordenação de Educação do Museu. ${ }^{4}$

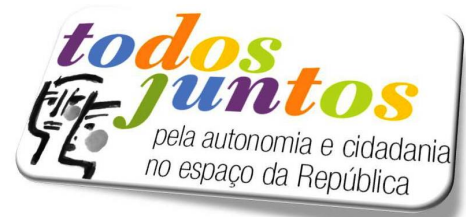

Figura 1 - Logo do projeto

Fonte: Equipe do Museu da República (2009).

\section{O projeto premiado: Educação e Trabalho - Uma Ação de Cidadania}

Em 15 de novembro de 2013, o Museu da República inaugurou a exposição "Trabalho, Luta e Cidadania: 70 Anos da CLT”, comemorando os 70 anos da criação deste importante documento legal para o país. A Consolidação das Leis do Trabalho, ou CLT, como é mais conhecida, foi a organização e publicação em um documento legal das diversas leis sobre o trabalho já existentes. A CLT foi promulgada em 1943. A CLT foi um resultado das lutas dos trabalhadores no Brasil, um marco na luta dos trabalhadores pela conquista e reconhecimento de direitos trabalhistas e sociais no Brasil.

A exposição abordava a questão do trabalho desde meados do século XIX até aquela data. ${ }^{5}$ Neste sentido, e num momento em que o mercado de trabalho, não apenas no Brasil, mas no mundo, atravessava tantas mudanças, pareceu-nos bastante oportuno propor atividades educativas que favorecessem uma maior reflexão sobre os temas trabalho e cidadania, bem como suas interrelações, a partir da citada exposição.

O Setor Educativo do Museu da República desejava, mais uma vez, desenvolver um novo projeto com os alunos do CIEP Tancredo Neves, a exemplo do ano de 2009, quando trabalhou com todos os alunos dessa Escola (turnos diurno e noturno) em um projeto pautado na Constituição Brasileira, como já mencionado. A exposição sobre a luta dos trabalhadores para a Consolidação das Leis do Trabalho (CLT) apresentou-se como uma excelente oportunidade para retomar a parceria com essa Escola. E tendo em vista as especificidades do assunto, ao se pensar nas atividades a serem desenvolvidas em torno da exposição, não se teve dúvida em tratar o tema com alunos trabalhadores: assim, decidiu-se desenvolver um projeto específico Educação e Trabalho: Uma Ação de Cidadania com os alunos do Programa de Educação de Jovens e Adultos (PEJA) do CIEP Tancredo Neves, onde o PEJA funciona, como na grande maioria das escolas públicas municipais, no horário noturno.

Como já assinalado anteriormente, os alunos do PEJA são alunos trabalhadores: empregadas domésticas, faxineiros, taxistas, porteiros, vendedores ambulantes, entre outros, cuja idade 
varia entre 15 e 70 anos de idade. São moradores do bairro e arredores onde se situa o Museu, a maioria em favelas do bairro. O CIEP Tancredo Neves mantinha no turno da noite 08 (oito) turmas de Educação de Jovens e Adultos, cada uma com cerca de 30 (trinta) alunos. Novamente, alunos que não conheciam o Museu. Jovens e adultos que nunca pisaram num museu ou por falta de tempo ou por não se sentirem convidados ou mesmo por não sentirem ter direito a fazê-lo. Além disso, o Museu não abria à noite porque não havia recurso para pagar segurança à noite. Isto acontecia e ainda acontece em muitos outros museus. Neste sentido, estudantes que estudam à noite não os visitam.

O Projeto foi proposto à Escola em novembro/2013 e foi construído pela Coordenadora do Setor Educativo, Normanda Freitas, com a participação efetiva dos professores do PEJA, em 05 (cinco) encontros, nos quais se construiu o planejamento de atividades e metodologias apropriadas para o desenvolvimento do tema "Trabalho e Cidadania". Assim, pode-se considerar, no Projeto, este momento como a primeira etapa. Durante as reunióes iniciais com os professores, a informação mais uma vez confirmada foi a de que nenhum dos alunos conhecia o Museu da República ou nenhum outro Museu.

O projeto foi desenvolvido de 07 de fevereiro de 2014, quando as aulas começaram, até 05 de maio.

O projeto "Educação e Trabalho: Uma Ação de Cidadania" foi desenvolvido junto a 240 estudantes do PEJA. Estes estudantes eram divididos em duas categorias: PEJA I, compreendendo os primeiros anos da escola primária (alfabetização ao quarto ano), e PEJA II, compreendendo as séries seguintes (do sexto ao nono ano).

O primeiro grupo era composto por adultos de até 70 anos, que se encontravam afastados da escola há muitos anos, ou aqueles que nunca a haviam frequentado. $\mathrm{O}$ segundo grupo era composto por grande quantidade de jovens que abandonaram o sistema regular de ensino e que tardiamente retornavam a ele. Esse segundo grupo evidencia o processo de evasão e/ou repetência do ensino formal, mas também faz um diagnóstico da necessidade cada vez maior da entrada precoce de jovens no mercado de trabalho.
Quanto à inserção no mercado de trabalho desse público, repetimos, encontramos essencialmente empregados de pequenos comércios, faxineiros, empregadas domésticas, taxistas, porteiros, vendedores ambulantes entre outras profissões.

O local de residência desse contingente de alunos-trabalhadores eram os bairros do Catete, Glória e Flamengo, sendo a maioria residente em comunidades (favelas) do Morro Santo Amaro e Tavares Bastos, ambos no Catete, e Morro Azul, no Flamengo. O Museu da República se situa no bairro do Catete.

Assim, foi importante desenvolver o tema do projeto centrado em atividades dinâmicas e bem planejadas, com linguagens claras e objetivas, de forma a atender os vários níveis de escolaridade (da alfabetização ao 9o ano). Além disso, nosso público era formado por mulheres e homens trabalhadores que chegavam para as aulas após um dia intenso de trabalho, ávidos por informaçôes que pudessem contribuir, em curto espaço de tempo, para seu desenvolvimento pessoal.

O principal recurso foi a exposição "Trabalho, Luta e Cidadania: 70 anos da CLT” e, a partir dela, Educadores do Museu e Professores do CIEP levaram aos alunos informações e reflexões sobre a história do trabalho no Brasil, direitos e deveres do trabalhador brasileiro, adequação das leis trabalhistas em relação à então recente legalização de profissóes como, por exemplo, a de empregados domésticos.

Foram usados, no projeto, recursos como filmes e rodas de conversa. Os professores tinham a liberdade de escolha para desenvolver um aspecto relacionado ao tópico, mas tendo como um princípio a ideia que perpassou e marcou todo o projeto: educação como um processo de conquista $\mathrm{e}$ de direitos e sua aplicação nas aquisiçôes do trabalhador.

O projeto tinha como objetivo geral desenvolver açôes que dessem oportunidades àquele público específico em acessar informação sobre trabalho e leis e a apropriação de habilidades e atitudes críticas reflexivas, essenciais para o seu desenvolvimento na escola, no trabalho e na vida social.

Entre os objetivos específicos, destacamos como os mais importantes: 
- estimular reflexões, questionamentos e debates sobre os direitos e garantias do trabalhador que estavam expressas na CLT, em contraponto à realidade que, em muitos casos, aponta para o não cumprimento das leis.

- dirigir aos estudantes temas tais como cidadania, autonomia, direitos e deveres dos trabalhadores brasileiros.

- encorajar os estudantes do PEJA, suas famílias e amigos a conhecer e frequentar o Museu da República.

O Projeto envolveu de forma direta todos os educadores do Setor Educativo. ${ }^{6} \mathrm{O}$ trabalho dos educadores foi apoiado por colegas de outros Setores, como Pesquisa e Museologia.

O projeto foi desenvolvido simultaneamente pelos professores do CIEP em sala de aula e pelos educadores do Museu no próprio Museu, a partir de açôes educativas específicas, comuns à educação formal do CIEP e à educação patrimonial do Museu. É importante registrar que todas as atividades que foram desenvolvidas no Museu aconteceram à noite, no horário de aula dos estudantes.

As atividades foram divididas em 3 fases: Preparação - Sensibilização, Execução e Avaliação.

\section{Fase 1 - Preparação - Sensibilização}

Os professores foram estimulados pela Direção do CIEP e pelo Museu a planejarem atividades para serem desenvolvidas em sala de aula, com o tema Trabalho e Cidadania, explorando o seu contexto histórico, político e social. Para tanto, a equipe de Educação do Museu da República disponibilizou aos professores todo o apoio necessário ao planejamento das atividades. Esse apoio se deu por meio de reuniôes, palestras, doação de um exemplar da CLT e de material bibliográfico com conteúdos referentes ao tema sobre trabalho.

Os alunos do Programa Educação de Jovens e Adultos conheceram pela primeira vez o Museu da República por meio de visitas mediadas ao circuito expositivo de longa duração. As visitas aconteceram no período da noite, no horário de aula dos alunos.

Em um só dia, todos os alunos do Programa Educação de Jovens e Adultos, divididos em grupos de 20 participantes, conheceram os salóes do Palácio do Catete e o circuito expositivo de longa duração do Museu por meio de visitas mediadas. ${ }^{7}$ Propositalmente, nesse dia não foi apresentada aos alunos a Exposição Trabalho, Luta e Cidadania: 70 anos da CLT, pois nosso planejamento foi trabalhar essa exposição na 2a fase do projeto. Conseguimos recursos para pagar a vigilância noturna nesse dia. Aliás, os recursos para esse projeto foram mínimos, em torno de $\mathrm{R} \$ 2.000,00$ (dois mil reais).

A mediação participativa aplicada na visita com os grupos discutiu temas como a história da construção do Palácio, o cotidiano dos primeiros proprietários, os conflitos de classes trabalhadoras existentes no período imperial com o trabalho escravo, a chegada dos imigrantes $e$ as transformações ocorridas com a abolição da escravatura e o trabalho assalariado. Essas questões, trabalhadas na mediação da visita ao Palácio, muito nos ajudou a potencializar o momento educativo, processado por meio da difusão de informaçốes históricas, aprofundadas posteriormente no desenvolvimento das atividades.

\section{Fase 2 - Execução}

Procuramos preservar as práticas pedagógicas utilizadas no ensino formal e não-formal, buscando adaptá-las a metodologias que valorizassem os conhecimentos e as vivências adquiridas, tanto na escola quanto fora dela, numa perspectiva que contemplasse a pluralidade de saberes, de forma a possibilitar maior troca de experiências entre os estudantes.

As atividades foram planejadas com graus de complexidades adequadas ao nível de escolaridade de cada turma, interesse dos participantes e em compatibilidade com o horário escolar noturno.

Tivemos por meta desenvolver um trabalho integrado entre o Museu da República e o CIEP Tancredo Neves, com açóes simultâneas realizadas pelos professores do CIEP e pelos educadores do Museu, da forma a saber:

Atividades propostas pelo Museu

1. Visitas mediadas

Realizadas com todos os professores do PEJA do CIEP Tancredo Neves à exposição "Trabalho, 
Luta e Cidadania: 70 anos da CLT”. Antecedeu a visita uma recepção aos professores no Espaço Educação, onde conversamos mais uma vez sobre o projeto e apresentamos registros fotográficos de outras parcerias de trabalho com o CIEP Tancredo Neves. Na sequência, os professores participaram da visita programada, mediada pelo curador da exposição, o pesquisador Marcus Macri.

Os alunos retornaram ao Museu em grupos de trinta participantes (dois grupos por dia), em dias alternados, para conhecerem a exposição "Trabalho, Luta e Cidadania: 70 anos da CLT”, mediados por educadores do Museu. Para essas visitas, pudemos dispensar a segurança noturna, permanecendo com somente dois funcionários de segurança do Museu, além dos alunos entrarem pela parte de trás do Museu e indo diretamente para as salas da exposição.

Nessa fase do trabalho, as visitas tiveram por intuito recorrer à narrativa da Exposição como fonte e aporte teórico para o desenvolvimento das atividades na escola.

\section{Balcão de Atendimento Jurídico}

Atendendo ao pedido dos professores, um educador do Museu que tem como segunda formação profissional a advocacia, foi ao CIEP Tancredo Neves uma vez por semana, no horário das 19:00h às 22:00h, ficando à disposição dos alunos para esclarecimento de dúvidas sobre as leis trabalhistas e consultas sobre o acompanhamento de causas jurídicas trabalhistas demandadas pelos estudantes.

\section{Painel Fotográfico}

Com o propósito de incentivar os alunos a participarem das atividades propostas pelo Projeto, o Museu da República instalou, no CIEP, um painel com as fotografias dos alunos participando das atividades na escola e no museu. O Painel Fotográfico foi atualizado semanalmente pelos educadores do Museu da República.

\section{Rodas de Conversas}

No decorrer dos trabalhos foram oferecidas, aos alunos e professores, "rodas de conversas" onde pequenos grupos de alunos puderam expor, para discutir no grupo, temas sobre suas experiências de trabalho envolvendo casos de descumprimento de seus direitos trabalhistas, sobre a questão da exploração da mão de obra infantil, sobre a recente conquista da inclusão do trabalho doméstico amparado por lei, sobre as consequências para patrôes e trabalhadores do descumprimento das leis trabalhistas, entre outras abordagens propostas por professores ou grupos de alunos.

\section{5- Diversos}

Ações de apoio, orientação, acompanhamento, documentação fotográfica de todas as atividades desenvolvidas pelos professores em sala de aula.

Os professores escolheram trabalhar 12 temas: Trabalho Infantil; Trabalho Feminino; Trabalho Informal; Profissões e Tecnologias; DIP (Departamento de Imprensa e Propaganda, no governo Getúlio Vargas); Relações entre os Sindicatos e o Estado brasileiro; Trabalho rural; Saúde do Trabalhador; Trabalhadores: organização sindical, moradias, formas de sociabilidade e lazer; As vilas e bairros operários: as transformações na geografia da cidade do Rio de Janeiro; CLT: aspectos positivos e negativos; O Mundo do Trabalho Hoje: a flexibilização das leis trabalhistas.

Os professores decidiram que os alunos do PEJA I trabalhariam com os temas: Trabalho Informal; Trabalho Feminino; Profissões e Tecnologias

Os professores do PEJA II decidiram que os alunos seguiriam uma outra dinâmica. Como os professores lecionavam disciplinas específicas e atuavam em todas as turmas, eles escolheram vários temas, que seriam trabalhados de forma integrada entre eles. Os temas escolhidos foram: Saúde do Trabalhador (Ciências); Profissões e Tecnologias (Matemática); Trabalhadores: Organização Sindical, Moradias, Formas de Sociabilidade e Lazer; As Vilas e Bairros Operários: as transformaçóes na geografia da cidade do Rio de Janeiro (Geografia); DIP (Português); Trabalho Infantil; Trabalho Rural; CLT: Aspectos Positivos e Negativos; O Mundo do Trabalho Hoje: a flexibilização das leis trabalhistas; Relaçóes entre os Sindicatos e o Estado Brasileiro (História)

Coube ao Museu da República apoiar os professores em suas ações, tanto na Fase de Preparação por meio de doação de material 
informativo sobre as Leis Trabalhistas, reuniões de planejamento conjunto de atividades para o projeto, quanto na Fase de Execução do Projeto, em que esse apoio se deu a partir de doação de materiais necessários ao desenvolvimento dos trabalhos propostos pelo CIEP e realizados em sala de aula, tais como papéis, cartolinas, colas, lápis de cor, fotografias, entre outros.

\section{6 - Exposição}

Montagem e divulgação da exposição "EDUCAÇÃO E TRABALHO", realizada no Espaço Educação do Museu da República, fruto do resultado final de todas as ações desenvolvidas no Projeto, na qual foram expostos fotografias, trabalhos dos alunos e um vídeo com a memória do projeto.

\section{Fase 3 - Avaliação}

Durante o desenvolvimento do projeto foram sendo feitas avaliações e algumas atividades foram modificadas. Por exemplo, haviam sido pensadas algumas palestras sobre alguns temas, mas percebeu-se que os estudantes davam preferência por falar sobre seus problemas e, daí, as Rodas de Conversas tomaram o lugar de palestras. Os temas que seriam tratados em palestras eram abordados em meio às Rodas de Conversas.

Outro exemplo foi o que chamamos de Noites Culturais. Considerando que o segmento escolar participante do projeto não é frequentador de museus e nem desfruta com frequência de lazer cultural, oferecemos aos alunos exibição de filme pautado no tema Trabalho e Cidadania. Essa atividade teve seu desdobramento em sala de aula, por meio de debates efetuados pelos professores junto a seus alunos. Um filme solicitado pelos alunos foi "Lula, o filho do Brasil".

A avaliação, de um modo geral, se deu por meio de observação direta, levando em consideração itens como envolvimento dos participantes nas atividades propostas, frequência dos alunos nos dias de visitas ao Museu e nas demais atividades propostas pelo Projeto.

Documentação fotográfica e gravações em vídeo das atividades desenvolvidas no CIEP e no Museu.
Para avaliar no público trabalhado a "ideia de pertencimento", na primeira semana do Projeto, os educadores do Museu junto com os professores do CIEP pediram aos participantes para individualmente ou em grupos, responderem por escrito ou gravarem oralmente a resposta à pergunta: Onde eu me encontrei no Museu da República?. De posse desse material, os educadores do Museu analisaram as respostas e fizeram a tabulação para efeito de relatório e como fonte de informaçóes geradoras de futuras ações voltadas para esse mesmo público. A maioria dos estudantes indicou que eles se encontraram na própria exposição sobre a CLT. Isso nos conduziu a concluir que o tema falou diretamente às necessidades dos estudantes.

Sendo os alunos do PEJA, em sua maioria, trabalhadores, sabemos que a experiência com o trabalho começou em suas vidas muito cedo quando, ainda crianças, já eram responsáveis pelo cuidado da casa e dos irmãos mais novos. Muitos deles até acompanhavam seus pais ao trabalho e realizavam pequenas tarefas para auxiliá-los.

Trabalhos e pesquisas acadêmicas mostram que, em todas as regiôes do país, o trabalho é apontado pelos alunos da Educação de Jovens e Adultos (EJA) tanto como motivo para terem deixado a escola como razão para voltarem a ela. Assim, sem nenhuma dúvida, o tema Trabalho tem um lugar especial nas salas da EJA, mesmo que esse tema tenha desdobramentos como o desemprego, trabalhos temporários ou informais.

Nessa perspectiva, foi de extrema relevância levar aos alunos - trabalhadores do Programa de Educação de Jovens e Adultos do CIEP Tancredo Neves -, informações, reflexões, questionamentos e debates sobre a importância da legislação trabalhista, os diversos tipos de trabalho, a necessidade da permanência da CLT e a adequação dessas leis ao surgimento de novas profissóes e/ou reconhecimento de outras que por muito tempo permaneceram na informalidade.

Como resultados esperados, desejava-se:

- Alunos (e familiares) estabelecendo relaçóes com o Museu da República.

- Alunos conscientes dos seus direitos no trabalho como cidadãos. 
Como resultados obtidos, consideramos:

- Obtivemos o envolvimento participativo de todos os professores do Programa de Educação de Jovens e Adultos do CIEP Tancredo Neves, assim como a participação de $95 \%$ dos alunos do PEJA.

- Na inauguração da Exposição dos trabalhos dos alunos, realizada no dia 5 de maio de 2014, contamos com a presença da quase totalidade de alunos e seus familiares, tendo sido registrada no livro de assinatura a participação de 350 signatários.

- Consideramos que, ao longo das Rodas de Conversa, pudemos observar a tomada de consciência dos seus direitos, pelos alunos.

\section{Sustentabilidade}

Diante do êxito do trabalho e em função do total envolvimento e entusiasmo dos Educadores do Museu no Projeto EDUCAÇÃO E TRABALHO: Uma ação de cidadania, o Setor de Educação do Museu da República planejou para 2014, bem como para os anos subsequentes, um atendimento sistemático a esse segmento de público, de forma a contemplar não só o do CIEP Tancredo Neves, mas também o de outras escolas que atendem ao PEJA. Para tanto, foi solicitado ao IBRAM, no orçamento anual, verba para projetos especiais no qual esse atendimento estava inserido. Não foi possível obter tais recursos.

Entretanto, ao receber o V PRÊMIO IBERO-AMERICANO DE EDUCAÇÃO E MUSEUS 2014 ${ }^{9}$, no valor de 10.000 dólares ( $\mathrm{R} \$$ 25.601,00), foi possível revertê-lo integralmente no atendimento ao Programa de Educação de Jovens e Adultos que se desejava realizar.

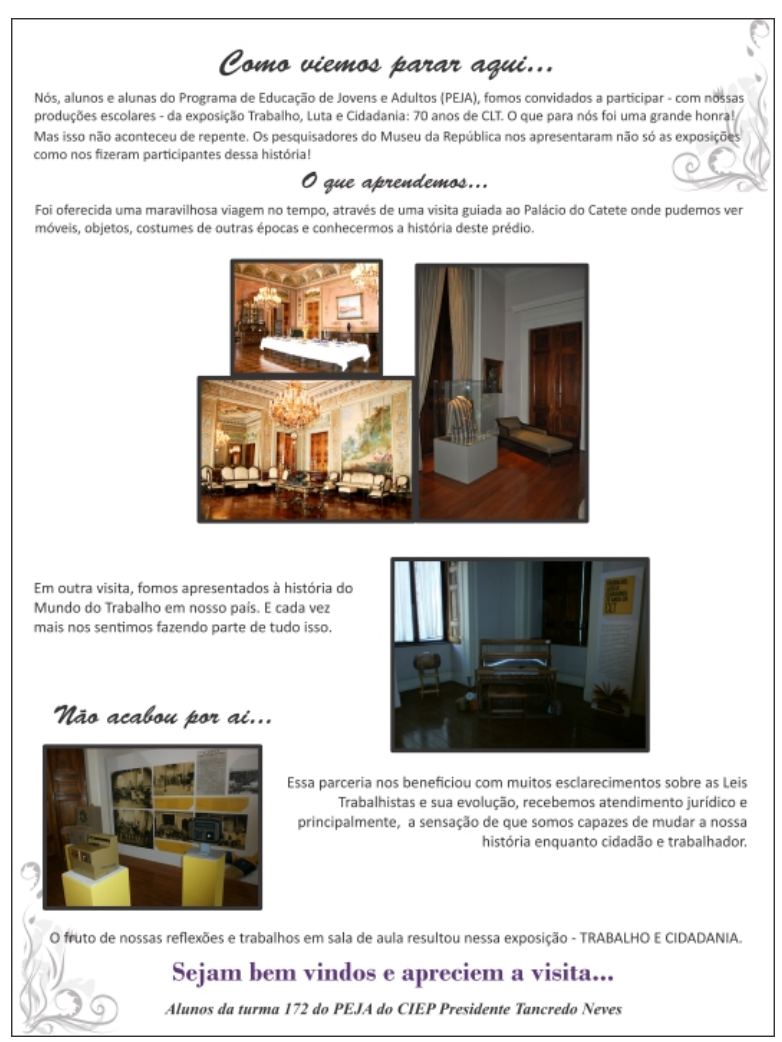

Figura 2 - Painel introdutório à exposição dos trabalhos dos alunos.

Fonte: Equipe do Museu da República (2014).

\section{O resultado do Prêmio: o projeto PEJA: Uma lacuna nos museus}

Se, ao final do projeto "Educação e Trabalho: Uma Ação de Cidadania”, havia a determinação de trabalhar mais diretamente com estes estudantes, com o recebimento do prêmio e os recursos financeiros que advieram dele, o Museu da República se sentiu, mais do que nunca, comprometido a dar continuidade e ampliar a sua relação com outros PEJAs da cidade do Rio de Janeiro, com o objetivo de conscientizar professores do PEJA e Educadores de Museu em geral para trabalhar a favor da inclusão sociocultural destes estudantes numa base regular, promover uma relação mais engajada entre educadores de museus e professores de PEJAS, e buscar sensibilizar as autoridades no apoio à abertura dos museus num dia da semana, à noite.

O prêmio trouxe a possibilidade de repetir o trabalho, desta vez atingindo mais escolas e em outros pontos da cidade do Rio de Janeiro, onde se 
pudesse conseguir transporte mais rápido para receber esses visitantes em seu horário escolar, ou seja, à noite. E foi com essa intenção que se começou a desenvolver o projeto "Museu para Todos", dirigido com exclusividade aos alunos do PEJA do Ensino Fundamental do município do Rio de Janeiro. O projeto estava estruturado por açóes pautadas no patrimônio histórico, artístico e social que o próprio Museu da República e seu rico acervo representam. Essas ações foram cuidadosamente planejadas, respeitando as dimensóes sociais, econômicas, culturais, cognitivas e afetivas do jovem e do adulto em situação de aprendizagem escolar, em consonância com os postulados progressistas de Paulo Freire.

Como a exposição sobre a CLT já tivesse sido desmontada e tendo em vista que no projeto "Educação e Trabalho: Uma Ação de Cidadania” os alunos do PEJA do CIEP Tancredo Neves responderam, em sua grande maioria, que onde eles se encontraram no Museu da República foi na exposição "Trabalho, Luta e Cidadania: 70 Anos da CLT", decidiu-se que a exposição motivadora a ser levada para os CIEPs compreenderia também o tema do trabalho e da CLT, além das relaçôes entre os salóes do Museu da República e o mundo do trabalho, situação em que a grande maioria dos alunos estava inserida, motivo pelo qual estudavam à noite.

Quando o projeto estava sendo estruturado, a diretora Magaly Cabral, ao participar como palestrante do Curso de Pós-Graduação em Educação Museal, realizado pelos Museus da República e Castro Maya, em parceria com o Instituto Superior de Educação do Estado do Rio de Janeiro (ISERJ), trouxe a proposta de uma aluna desse curso, Débora Lopes, museóloga e professora do PEJA, que sugeria a formação de alunos do PEJA como mediadores para receber seus colegas em visita a museus. Proposta aceita, o projeto foi redesenhado, incluindo a formação dos alunos como mediadores para os colegas do PEJA, conforme será visto a seguir no desenho do projeto. Também o nome do projeto foi mudado: de "Museu para Todos" passou a ser "PEJA: uma lacuna nos Museus". Assim, em 2015 foi desenvolvido o projeto "PEJA: Uma Lacuna nos Museus".
Inicialmente, o Projeto seria desenvolvido com os CIEPs Tancredo Neves, vizinho ao Museu, e Gregório Bezerra, localizado no bairro da Penha da cidade do Rio de Janeiro, onde a citada professora Débora Lopes trabalhava.

Outras duas Instituiçóes de Ensino - Escola Municipal Jenny Gomes, participante do ProJovem, localizada no Rio Comprido, e Centro Municipal de Referência de Educação de Jovens e Adultos (CREJA), localizado no Centro da Cidade do Rio de Janeiro - foram acrescentadas, a partir de reunião na Gerência da Educação de Jovens e Adultos da Secretaria Municipal de Educação da cidade do Rio de Janeiro, quando se cumpriu a Etapa 1 da Fase 1 do Projeto: apresentar o projeto à Gerência. Desta reunião participaram ainda a Direção do CREJA e a Coordenação do ProJovem.

O Projeto "PEJA: Uma lacuna no Museu" compreenderia a preparação dos alunos mediadores; recebimento nos CIEPs de exposição motivadora em forma de banners; visita ao Museu da República mediada pelos alunos mediadores. Outras atividades poderiam surgir, propostas pelos alunos $\mathrm{e}$ professores dos CIEPs.

Propôs-se que, após a realização de todas as atividades, fosse organizado um Seminário no Museu da República, dirigido a Professores do PEJA e Educadores de Museus, para apresentação do projeto desenvolvido e promoção de uma aproximação entre estes profissionais.

O projeto teve como objetivo geral assegurar aos alunos do PEJA o direito de acesso ao museu, incentivando e fomentando a elevação do nível de consciência crítica e a reconstrução da sua auto-estima.

Entre os objetivos específicos,

- Possibilitar aos alunos mediadores se perceberem como produtores e herdeiros de culturas produzidas não apenas pela comunidade a que pertencem, mas produzidas por outras comunidades e povos.

- Desenvolver junto aos alunos mediadores a construção do conhecimento sobre si mesmo, do outro e com o outro.

- Abordar e debater junto aos alunos e professores do PEJA temas como patrimônio, cidadania, autonomia, direitos e deveres dos trabalhadores brasileiros. 
- Estimular os alunos participantes a frequentarem o Museu da República e outros museus, levando seus familiares e amigos.

O desenvolvimento do projeto teve as seguintes fases previstas:

\section{Fase 1: Preparação}

$\mathrm{Na}$ fase de preparação seriam mobilizados recursos como mobilização da equipe de trabalho, reserva de espaço para realização das atividades, compra de materiais, preparação de atividades. A fase de preparação do projeto consistiria de duas etapas:

Etapa 1: Apresentação da proposta

O Projeto seria apresentado às diversas instâncias envolvidas :

1 - Gerência de Educação de Jovens e Adultos (GEJA) da Secretaria Municipal de Educação.

2 - Direçóes dos CIEPs Tancredo Neves e Gregório Bezerra.

Aprovado o Projeto,

1- Reuniôes com os Professores do PEJA dos CIEPS, da Escola Municipal Jenny Gomes e do CREJA para apresentação e discussão do Projeto, com incorporação de sugestóes.

2 - Convite aos alunos a participarem do projeto para atuarem como mediadores e entrevistá-los. Foram convidados 6 alunos: 3 alunos do CIEP Gregório Bezerra, 2 alunos do CREJA e 1 aluno da Escola Municipal Jenny Gomes.

Estes alunos deviam dispor de tempo livre diurno.

Os alunos receberiam apoio para transporte e alimentação.

EM TEMPO: Após a Reunião na Gerência de Educação de Jovens e Adultos (GEJA), quando foram acrescentadas novas Escolas, recebemos e-mail do CIEP Tancredo Neves informando que não seria possível ter a participação de alunos no horário diurno.

Etapa 2: Operacionalização da exposição itinerante

Nessa etapa, seria preparada a exposição itinerante com cerca de 15 banners, enfocando o Museu da República enquanto lugar de memória e de produção de cidadania e uma adaptação da exposição "Trabalho, Luta e Cidadania: 70 anos de CLT”.

\section{Fase 2 - Execução}

A fase de execução do projeto consistiria em atividades envolvendo professores, alunos e educadores do Museu da República. Seria realizada em:

Etapa 1: Início da preparação do grupo de monitores.

A preparação foi estimada em levar cerca de dois meses.

Etapa 2: Visita mediada e encontro com professores

Nessa etapa, os educadores do Museu da República fariam uma visita mediada com os professores, enfocando a história do Palácio como um poderoso recurso didático, capaz de sensibilizar o público-alvo para questóes como a importância do patrimônio para a construção da identidade, a comparação do passado com o presente, o processo de construção da cidadania, além de tratar da exposição sobre a CLT.

Os educadores do MR discutiriam com os professores, no Museu, o detalhamento das etapas de desenvolvimento do projeto.

Etapa 3: Exposição itinerante

Nessa etapa, o Museu levaria a exposição itinerante para as duas escolas do PEJA e orientaria os professores a respeito da montagem dos banners.

Visita à exposição, mediada pelos alunos mediadores; acompanhamento dos educadores do Museu e dos professores.

\section{Etapa 4: Encontro com estudantes}

Visitas ao Museu mediadas pelos alunos mediadores; acompanhamento dos educadores do Museu.

Etapa 5: Discussões na escola

Professores e alunos discutiriam em suas turmas, e de forma autônoma, os temas motivados pela exposição itinerante. 
Etapa 6: Rodas de conversa

Após terem participado das etapas anteriores (exposição itinerante, discussóes em sala e visita mediada ao Museu), os alunos estariam prontos para a elaboração de uma reflexão embasada na experiência empírica e na coleta de informaçóes sobre os temas trabalhados no projeto. O objetivo dessa etapa seria o empoderamento dos alunos, no sentido de permitir que eles compreendessem que sua voz, enquanto cidadáos participantes, merece ser ouvida e valorizada.

As rodas de conversa aconteceriam após a visita ao Museu e na Escola.

\section{Etapa 7: Exposição (Opcional)}

Se os Professores e os Alunos dos CIEPs desejassem e se fossem produzir materiais passíveis de serem expostos, poderia ser montada uma exposição no Espaço Educação do Museu da República.

O objetivo dessa atividade seria fazer com que os alunos tivessem uma noção dos variados aspectos envolvidos no processo de montagem de uma exposição num museu. Os alunos poderiam expor fotos, trabalhos realizados, redaçôes, etc. Como desdobramento desse objetivo, os alunos deveriam perceber que o seu empoderamento, enquanto sujeitos cidadãos, está também relacionado com a capacidade de selecionar conteúdos que eles considerassem relevantes, numa perspectiva de valorização da autonomia.

\section{Etapa 8: Avaliação}

A avaliação seria feita permanentemente, pela observação direta nas atividades, com anotaçôes.

Seriam elaborados questionários de avaliação:

- Para os Professores dos PEJAs;

- Para os Educadores do Museu;

- Para os Alunos participantes;

- Para os Alunos Mediadores.

\section{Etapa 9: Seminário}

Realização de um Seminário dirigido a Professores do PEJA e Educadores de Museus para apresentação do Projeto, avaliação e promoção de uma aproximação entre estes profissionais.

Os Alunos participantes seriam convidados a participar.
O Seminário deveria ser realizado no horário noturno, de forma a permitir a participação de Professores e Alunos dos PEJAs.

\section{Avaliação final do Projeto}

O Projeto teve início em setembro de 2015 e, por razóes alheias à vontade da Equipe do Setor Educativo do Museu, somente foi finalizado em março de 2017, com a realização do Seminário de avaliação.

$\mathrm{Na}$ Fase 1 - Preparação, não foi possível reunir os professores das escolas envolvidas. $\mathrm{O}$ projeto foi apresentado à Direção de cada escola, pela diretora do Museu. Também não houve a reunião com os professores, prevista na Fase 2, Etapa 2 do projeto.

Na Etapa 3 da Fase 2, os educadores do Museu da República não puderam ir às escolas para apresentar a exposição aos alunos.

Considerou-se, após a realização do projeto experimental, a necessidade de se ampliar o número de encontros para explorar o tema em questão. Percebeu-se que foi um tempo curto para trabalhar com as alunas todo o conteúdo programado (oito encontros - minicurso), já que foram abordados temas pouco, ou nunca, explorados na vida acadêmica delas. Uma grande quantidade de informaçóes que thes eram alheias provocou certo grau de cansaço mental; isso foi especialmente demonstrado nos momentos em que elas solicitavam a repetição de informaçôes já trabalhadas ou demonstravam dificuldade em recorrer aos assuntos já tratados nos encontros anteriores. É necessário frisar, contudo, que a quantidade de oito encontros possibilitou que as alunas participassem do projeto, organizando sua vida pessoal e laboral para que não se ausentassem de nenhum encontro, não chegassem ao cansaço físico extremo, tendo que lidar com horas no trânsito para chegar ao Museu da República e, ainda, assistir normalmente às aulas nas suas unidades escolares. Algumas, inclusive, pontuaram oralmente que o fato de o projeto ter sido planejado para dois meses foi determinante para sua participação; se fosse um projeto com um período maior de realização, sua participação ficaria comprometida. 
Outra questão importante e que causou debate entre parte da equipe do projeto foi em relação à compreensão dos seus objetivos. Alguns educadores do Museu da República pontuaram oralmente, em alguns momentos, sua preocupação em relação à quantidade e qualidade das informaçóes que seriam trabalhadas durante a visita mediada pelas alunas. Entretanto, conforme foi avaliado no item anterior, o número de encontros atendeu às expectativas. Segundo a professora Débora, foi possível perceber, pouco a pouco, na troca de experiências, que tudo o que as alunas viram e viveram, passível de desdobramentos e trocas, foi sendo colocado de lado em detrimento das informações sobre o Museu da República. Os educadores do Museu discordaram da professora, dizendo que não houve preciosismo. Não houve discordância sobre a importância de informaçóes e conteúdos que podiam ser disponibilizados pelo Museu.

A professora Débora comentou que quando escreveu o projeto referente ao minicurso de mediação, não objetivava oportunizar aos sujeitos da EJA experiências que eles normalmente têm tido ao visitar espaços culturais, a saber: a escola em geral recebe o convite para participar de uma atividade $\mathrm{X}$ ou Y e participa da atividade sendo mera receptora do que a instituição preparou para os alunos. Nesse projeto, comentou a professora, a ideia era construir o caminho inverso e, por isso, inovador: a escola, na figura de uma professora, construiria uma parceria que possibilitasse uma experiência diferente, na qual os alunos não fossem meros receptores, e sim construtores ativos do processo. Segundo ela, o minicurso de mediação contribuiu para tornar as alunas protagonistas do processo: elas pensaram não apenas em suas próprias estratégias para realizar a visita mediada, como também participaram ativamente do planejamento e da construção do roteiro da visita. A visita era o momento em que todos os sujeitos da EJA não apenas teriam acesso ao espaço em horário noturno, mas, principalmente, seriam protagonistas dessa visita; isso porque, na troca de experiências com as alunas mediadoras, ambos os lados constroem juntos, ambos são importantes e protagonistas. Logo, insistiu a professora, a ideia de que as alunas "aprendessem", "decorassem”, enfim, “disponibilizassem” o máximo de informação possível do acervo e do complexo arquitetônico aos seus colegas estava fora de cogitação da proposta inicial do projeto.

Com relação aos banners, projeto inicial do Museu da República, a professora teceu muitos elogios, dizendo que foram de extrema importância para a aproximação dos alunos na unidade escolar, para o despertar de sua curiosidade, para o convite e a aceitação do projeto. Segundo a professora, o material não foi apenas esteticamente pensado, com visual atraente e textos sucintos, com letras grandes, mas o próprio conteúdo foi elaborado para alunos da EJA, contemplando os interesses dos sujeitos, jovens e adultos trabalhadores. Segundo a professora, a visita ao Museu da República foi uma das atividades com maior quórum no ano de 2015 entre as realizadas pelo CIEP em que ela trabalha.

Com relação aos temas trabalhados, a professora não faria acréscimos e disse que a contribuição enfática dos educadores do Museu da República foi de suma importância na construção dos temas com o grupo. Ela destacou a participação do educador Carlos Xavier no primeiro encontro, que deixou o grupo à vontade no primeiro contato, assim como a participação do educador Marcelo Pereira, em todos os encontros, pois, além das informaçôes importantes que compartilhou com o grupo, ele contribuiu com a construção de uma postura de segurança e confiança desse grupo. Ela observou ainda o apoio dado pela educadora do Museu da República, Kátia Frecheiras, lotada no Setor de Pesquisas como pesquisadora sobre educação em museus. A professora acrescentou também acreditar que o modo como os encontros foram pensados, sem muita exposição oral, foi positivo, não exigindo muita concentração das alunas.

De modo geral, os educadores do Museu da República consideraram que houve poucas reunióes de preparação e reflexão inicial do projeto e gostariam que tivesse havido uma construção coletiva.

Assim, é válido concluir que os objetivos a que nos propusemos atingir ao elaborarmos esse projeto foram atingidos. A acessibilidade dos alunos do PEJA ao Museu da República, por exemplo, tornou-se uma realidade, principalmente com a 
abertura do Palácio à noite na última terça-feira de cada mês.

\section{Ponderações das alunas mediadoras}

De acordo com a professora Débora, as alunas sentiram-se maravilhadas com toda a experiência e verbalizaram isso em vários momentos. Elas torciam para que houvesse continuidade do projeto e solicitaram à Direção do Museu da República que se pense num programa de estágio para alunos da EJA ou qualquer outro vínculo que lhes permita manter a mesma relação com esse espaço. De todos os encontros, elas avaliaram negativamente o encontro que deveria ser um bate-papo com profissionais. Disseram que muito do que foi dito não foi compreendido e que houve muito tempo de exposição oral, da qual elas não puderam participar (elas assistiram a uma gravação). Disseram-se esgotadas mentalmente.

Abaixo, algumas avaliaçóes das alunas mediadoras, feitas pela prof. Débora Lopes, a partir das perguntas:

- Você está apreciando as experiências que esse projeto está proporcionando? Gostaria que essas experiências continuassem a ocorrer nos próximos anos?

Sim! Com toda certeza essas experiências DEVEM ser multiplicadas mais e mais, pois temos o direito e o dever de conhecer, valorizar e zelar pelo que é nosso. Também gostaria que o conteúdo absorvido ao longo desse tempo (60 dias) fosse de alguma forma aproveitado pelo museu. Quem sabe uma nova porta de emprego especialmente para a EJA - Educação de Jovens e Adultos GRATA PELA ATENÇÃO A MIM DISPENSADA.

$\mathrm{Na}$ minha opinião foi uma experiência importante e foi um conhecimento muito bom e que outros eventos como esse poderiam acontecer.

Sim, estou apreciando as experiências e achando tudo muito interessante. Gostaria que essas experiências fizessem parte em minha vida e me ajudasse a crescer no mundo do trabalho, como por exemplo tendo a oportunidade de estagiar no museu, podendo realizar o que aprendi e aprenderei, principalmente convivendo com essas experiências e conhecimentos.

O seminário "PEJA: uma lacuna no museu" contou com a presença de 140 profissionais, entre professores do PEJA e educadores de museus. A Gerência de Educação de Jovens e Adultos (GEJA)/Secretaria Municipal de Educação da Cidade do Rio de Janeiro, o Centro Municipal de Referência de Educação de Jovens e Adultos (CREJA) e o CIEP Gregório Bezerra se fizeram representar e as professoras manifestaram-se sobre a importância do projeto para os alunos. Em seguida, a prof. dra. Marta Lima de Souza, da Faculdade de Educação da UFRJ, proferiu a palestra "Poetizar, criar, fruir, visitar, conhecer arte com jovens e adultos: pelo direito de ser mais!” (2017, 22-31). Após a palestra e o debate, foram apresentados o projeto e, em seguida, uma avaliação, que contou com a participação de três das quatro alunas mediadoras que participaram do projeto. Para finalizar, foi apresentada a proposta de dar continuidade ao atendimento a alunos do PEJA no Museu da República, que, desde 2016, abre toda última terça-feira do mês das $18 \mathrm{~h}$ às $22 \mathrm{~h}$. Propóe-se o atendimento, seja com uma visita mediada, seja com o desenho de um projeto especial e o empréstimo da exposição de banners sobre o Museu da República. $\mathrm{O}$ interesse apresentado pelos professores foi bastante significativo. Ao término do seminário, os participantes foram convidados a visitar o Museu da República, acompanhados pela equipe do Setor Educativo do Museu. 


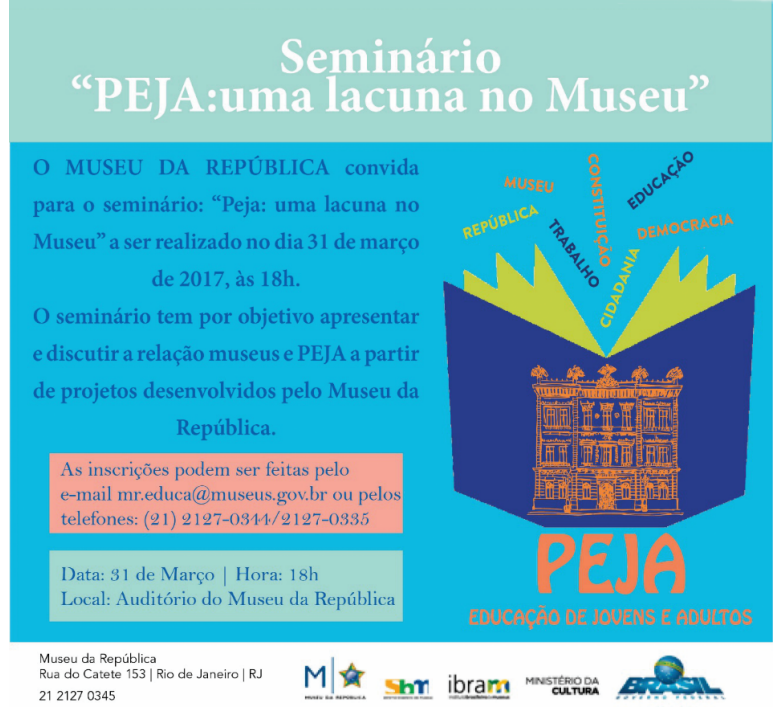

Figura 3 - Convite de divulgação do Seminário.

Fonte: Equipe do Museu da República (2017).

\section{Conclusão: PEJA e o futuro no Museu da República}

Podemos inferir que uma consequência do Prêmio recebido pelo Museu da República foi a obtenção de recursos para a abertura do Museu uma vez por mês à noite. Assim, ao longo de todo o ano de 2016 e 2017, toda última terça-feira do mês, das $18 \mathrm{~h}$ às $22 \mathrm{~h}$, o Museu da República abriu suas portas e recebeu 411 estudantes do PEJA, acompanhados de 42 professores.

No mês de outubro/2017, realizou-se um Encontro com professores do PEJA, numa sexta-feira à noite, dia da semana em que esses professores têm reunião para programar atividades. Compareceram 07 professores.

A Professora Débora Lopes, citada no terceiro projeto apresentado neste artigo, em sua Dissertação de Mestrado, defendida em maio/2018, intitulada "Entre o ver e o olhar: a relação dos museus com a Educação de Jovens e Adultos", comenta que o Museu da República vem realizando um trabalho ímpar e inovador no que tange a aproximar os museus da EJA, com projetos avaliados positivamente por seus educadores e alunos participantes. Comenta, ainda, que a crescente procura por visitas noturnas em seus espaços indicam que o caminho trilhado é de sucesso. E acrescenta que diante de um contexto de Política Nacional de Educação Musea ${ }^{10}$ que defende um acesso universalizado, como direito de todos, dentro de um ideal de acessibilidade plena, o Museu da República tem alçado um voo solitário, enquanto museu administrado pelo Ibram $^{11}$ na cidade do Rio de Janeiro, ao se preocupar com açôes (publicaçôes, projetos específicos, visitação noturna) com o foco nos sujeitos da EJA.

O Museu da República compreende os alunos da EJA, no universo escolar, como o que costumamos chamar de "público invisível" nos museus, ou seja, aquele público que está próximo, como os funcionários da limpeza, da segurança, etc., mas aos quais não se destinam programas para atendimento. O Museu da República compreende o atendimento aos alunos da EJA como um compromisso com o direito cultural desses alunos. Afastados da escola regular por diversas razões, não tiveram direito a visitar museus quando na idade de frequentar a escola e, agora, à noite, quando retomam seus estudos, após um dia cansativo de trabalho, não desfrutam desse direito porque os museus não abrem à noite. $E$ por que visitar museus? É tão importante para esses alunos visitar museus? Trata-se de usufruir do direito de visitar, de vivenciar a experiência e de poder decidir se desejam voltar ou não, se gostaram da experiência ou não. Museu é um espaço de encontro, de convivência e de reflexão. No museu, a partir dos objetos concretos, pode-se chegar a conceitos abstratos. Pesquisas demonstram que os escolares visitam museus levados por seus professores. O mesmo se dará com os alunos da EJA, se os museus estiverem abertos à noite para recebê-los. Uma vez por mês, que seja, já é um caminho para o futuro ${ }^{12}$.

\section{Notas}

1 Em 2014, Magaly Cabral, museóloga e educadora museal, era a diretora do Museu da República e Normanda de Freitas a coordenadora do Setor de Educação. Juntas, e com a equipe do Setor, desenvolveram o projeto, assim como os demais.

2 O período letivo no Brasil vai de fevereiro a dezembro.

3 Em 1985 foi eleito, por voto indireto, dada a derrota da proposta de emenda constitucional que garantiria o voto direto, o primeiro presidente civil, depois de mais de vinte anos de regime de exceção. $\mathrm{O}$ advogado, empresário e político mineiro Tancredo de Almeida Neves, opositor 
ferrenho da ditadura militar, tornou-se símbolo da esperança de um futuro com maior liberdade, de um governo finalmente democrático, que valorizasse ideais, como igualdade, autonomia, pluralidade. Entretanto, parte dessa esperança criada com a eleição de Tancredo Neves para a presidência foi frustrada com sua morte, no dia 21 de abril de 1985, antes de sua posse.

4 Com os recursos da Fundação Ford, foi possível contratar os educadores Raquel Luise Pret e Paulo Rigaud Navega, para elaboração e condução do projeto, sob a supervisão e orientação de Normanda Freitas Lira, Coordenadora do Setor de Educação.

5 Em 2017, a CLT sofreu alterações. Entraram em vigor reformas trabalhistas.

6 Além da Coordenadora, Normanda Freitas, os educadores Ana Paula Zaquieu, Carlos Xavier Daetwyler de Oliveira, Janete Costa Martins da Silva, Marcelo de Souza Pereira, Maria de Lourdes da Silva Teixeira e Rosângela Gonçalves Magalhães de Oliveira.

7 Não esquecer que os alunos nunca tinham visitado o Museu da República.

8 Lula era o presidente do Brasil, oriundo das classes trabalhadoras, metalúrgico.

9 O projeto recebeu, em 2015, o prêmio Best Practice, concedido pelo Comitê Internacional para Educação e Ação Cultural (CECA) do Conselho Internacional de Museus (ICOM), do qual a então Diretora do Museu, Magaly Cabral, é membro desde 1979.

10 A Política Nacional de Educação Museal (PNEM) foi resultado de discussóes entre educadores de museus do Brasil e lançada pelo Instituto Brasileiro de Museus, em 2017.

11 Instituto Brasileiro de Museus, responsável pelos museus federais subordinados ao antigo Ministério da Cultura, hoje Secretaria Especial da Cultura, subordinada ao Ministério do Turismo.

12 A Prof. Débora Lopes, em novembro/2020, ministrou, em colaboração com a Rede de Educadores em Museus (REM-RJ), um minicurso virtual para educadores de museus intitulado "O Museu em colaboração com a EJA: caminhos para a prática de uma educação transformadora”.

\section{Referências}

FREIRE, Paulo. Pedagogia da Autonomia: Saberes necessários à prática educativa. Editora Paz e Terra, 1996.
LOPES, Débora. Entre o ver e o olhar: a relação dos museus com a Educação de Jovens e Adultos. 2018, 158 f. Dissertação (Mestrado em Educação) Pontifícia Universidade Católica do Rio de Janeiro, Rio de Janeiro, 2018.

SOUZA, Marta Lima. Poetizar, Criar, Fruir, Visitar, Conhecer a Arte com Jovens e Adultos, pelo direito de Ser Mais! Revista do Professor - Edição Especial: Programa de Educação de Jovens e Adultos. Rio de Janeiro: Museu da República, 2017, p. 22-31. 